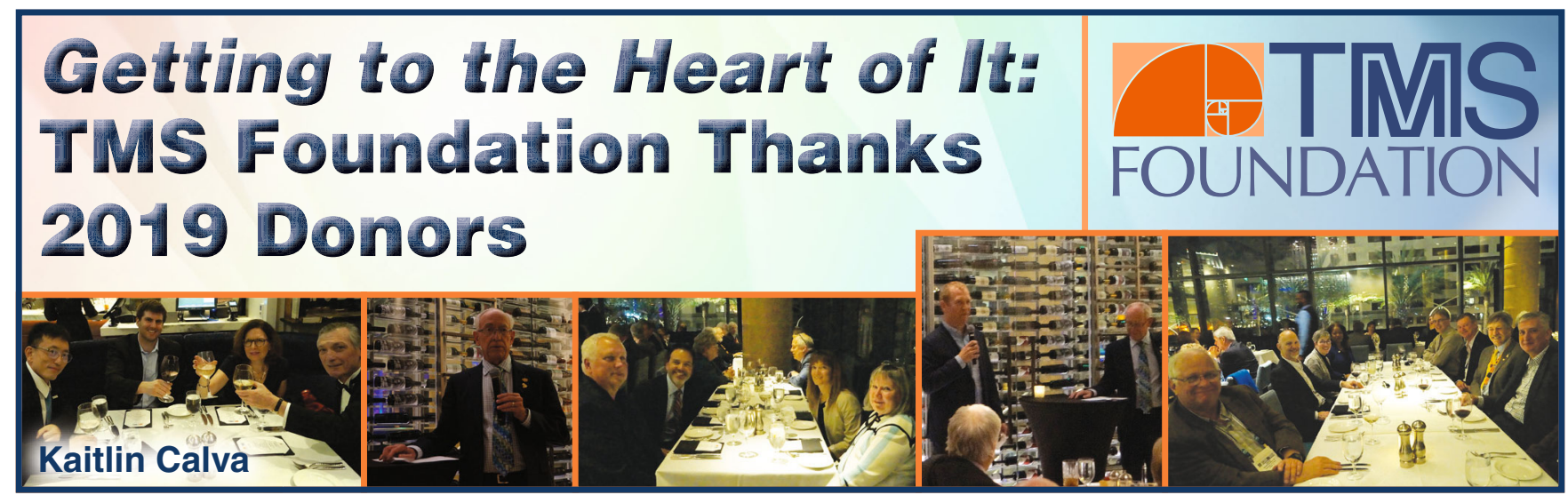

Each year, the TMS Foundation family gathers for its donor dinner event at the TMS annual meeting to celebrate those who make a difference. "You have distinguished yourselves as scientists, mentors, leaders, and philanthropists," said Garry Warren, TMS Foundation Board of Trustees Chair, as he welcomed and thanked the night's guests. "Your commitment to the TMS Foundation reflects your passion to introduce young people to the materials science and engineering community and to sustain them in the profession through their formative years."

The passion of these top donors is what keeps the TMS Foundation going; without their continued support, the Foundation could not provide the financial assistance, leadership development opportunities, or early career recognition that it does. Through this support at the most critical stages of career development, the Foundation is the steppingstone for many individuals to take on new roles

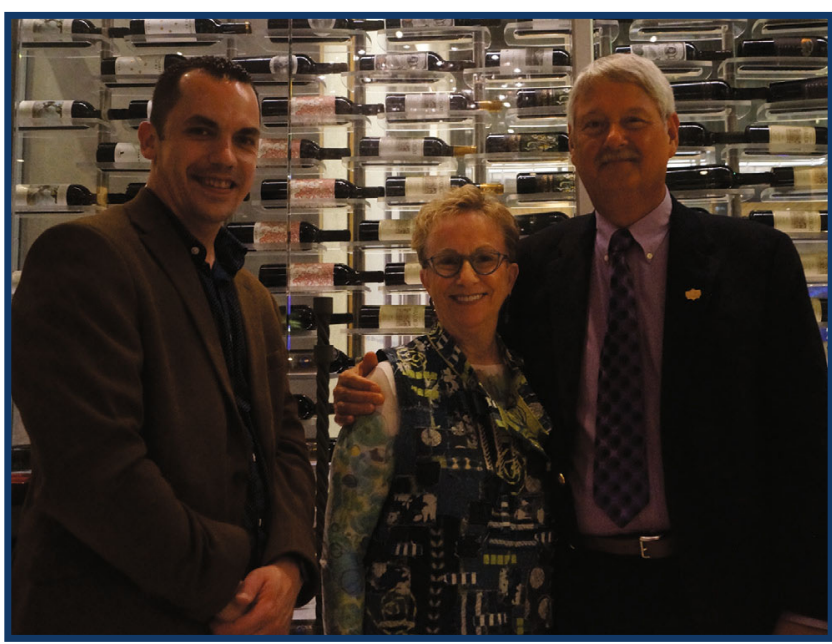

Robyn and Rob Wagoner (pictured above center, right) receive their pin as members of the TMS Foundation Diamond Society from Paul Ohodnicki (left), recognizing lifetime giving to the Foundation of $\$ 100,000$ or more. As constant supporters of the Foundation since its creation in 1995, Rob has served as chair of the Revitalization Committee and then as Board of Trustees chair. "We can proudly say that Rob is the architect of the Foundation's revitalization," said Garry Warren. "Rob strategized and urged the Foundation forward with vigor and determination, all the while donating generously." within their education, workplace, or the Society.

Warren then introduced Paul Ohodnicki, associate professor of mechanical engineering and materials science at the University of Pittsburgh, who benefitted from Foundation support as a 2010 Young Leaders Professional Development Award recipient.

"Receiving that award as a young engineer working in industry during the financial crisis provided me with an opportunity to attend both the TMS Annual Meeting and MS\&T at a time when it would have been too difficult for my employer to justify attendance. It also allowed me to become immersed in the TMS volunteer leadership activities and to expand my professional network within the TMS community," he said. "As an active TMS member, I subsequently took on a number of volunteer and leadership roles. And as a result of the connections and relationships built through my TMS involvement, I was able to identify a number of career opportunities within both the government and academic sectors."

Warren noted that Ohodnicki "is on a path we love to see-he first joined TMS as a student, he has stayed involved as a volunteer throughout school and career and is giving back as a donor." Ohodnicki added: "At this point in my career, I am actively donating to the TMS Foundation and also have accepted a position as chair of the Functional

\section{Join the Next Celebration}

The TMS Foundation Donor Recognition Dinner is held in conjunction with the TMS annual meeting to formally welcome new members to the TMS Foundation Lifetime Giving Honorific Societies and to thank all donors in the preceding year for their generosity and support. You can be a part of the next celebration at the TMS 2021 Annual Meeting \& Exhibition (TMS2021), March 14-18, 2021, in Orlando, Florida, by making a gift of $\$ 1,000$ or more or joining one of the TMS Foundation honorific societies.

To get special benefits as a TMS2021 attendee in addition to an invitation to the donor dinner, become a VIP Donor with a contribution of $\$ 2,000$ or more in 2020. Visit www.TMSFoundation.org for more details or to make a donation online today. 


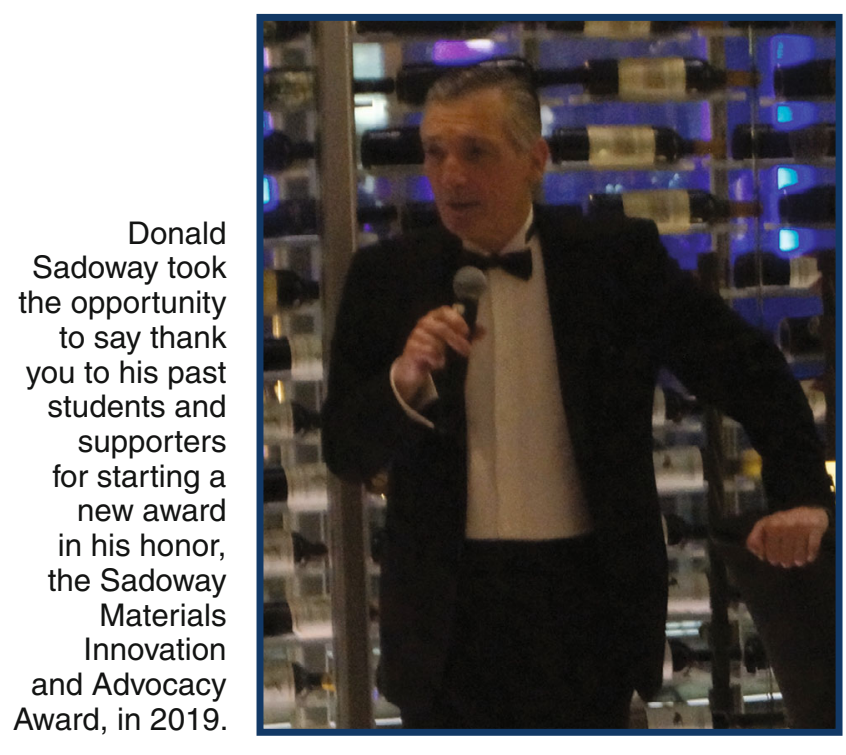

Materials Division and as a new Board of Directors member for TMS because I want to give back and ensure that the next generation of engineers can access the types of opportunities that I was privileged to receive as a young engineer."

Another highlight for the TMS Foundation in 2019 was the launch of fundraising efforts for a new Societylevel award - the Sadoway Materials Innovation and Advocacy Award, named in honor of Donald Sadoway. Jim Yurko, one of Sadoway's former students, shared his own experience with the TMS Foundation: "I have benefited tremendously from the TMS Foundation and its programs, which have helped me grow professionally and make great friends along the way with fellow materials professionals," he said. "As my career has progressed, it's been a priority to give back to the TMS Foundation and help the next generation."

Along with David DeYoung, a fellow past student of Sadoway's, Yurko is leading the fundraising for the award and acknowledged that the Foundation is the perfect home for such recognition opportunities. "If you think about the mission statement of the Foundation, and if you know Don Sadoway and his career path and focus, you easily spot an alignment. Education, mentorship, and support of students and young professionals. Promoting the field of materials science and its impact on society."

Sadoway also offered a few comments, thanking his past students and supporters of the award for their dedication to establishing such an honor in his name. "Throughout my career I've cultivated the notion that engineering is science in service to society, not science in service of career building - chasing after number of publications, number of citations. I'm thrilled that TMS has created this award to recognize people whose work embodies the fusion of engineering $R \& D$, engineering education, and technological advocacy," Sadoway said. "I am honored to see the establishment of a TMS award with my name on it. This is a humbling experience for me."

Before the end of the evening's festivities, Warren and Ohodnicki presented the 2019 TMS Foundation Lifetime Giving Honorific Society inductees with their society pins. "Please know that every thanks from a recipient to the Foundation echoes back to you. When they say, 'I hope to contribute to the field in the future,' you helped open that path to the future. When they say, "this gives credibility to my work and enriches my learning," you are the enricher. And when they say that they see the TMS Foundation as a great resource and system of support, you are the resource and support. You are the heart of the profession, and we thank you."

"As the top donors to the TMS Foundation, you provide opportunity and recognition for the enrichment and advancement of our membership," said Warren, reiterating the night's message of gratitude. "You are at the heart of this profession and give those who benefit a sense of belonging to something important. Thank you for your energy, philanthropic spirit, and caring."

The 2019 inductees are pictured below, left to right: Anne and Jonathan Dantzig, Silver Society; Mary and Robert Shull, Titanium Society; Robyn and Rob Wagoner, Diamond Society; Deepa and Brajendra Mishra, Gold Society; John Hryn, Silver Society; Joan and James Yurko, Titanium Society; Jim Foley, Silver Society; David Shifler, Gold Society; Luis Ortiz, Silver Society; and Antoine Allanore, Silver Society. Not pictured are: Cynthia Bognar, Titanium Society; David DeYoung, Titanium Society; Christopher Schuh, Silver Society; and Ingo Wender, Silver Society.

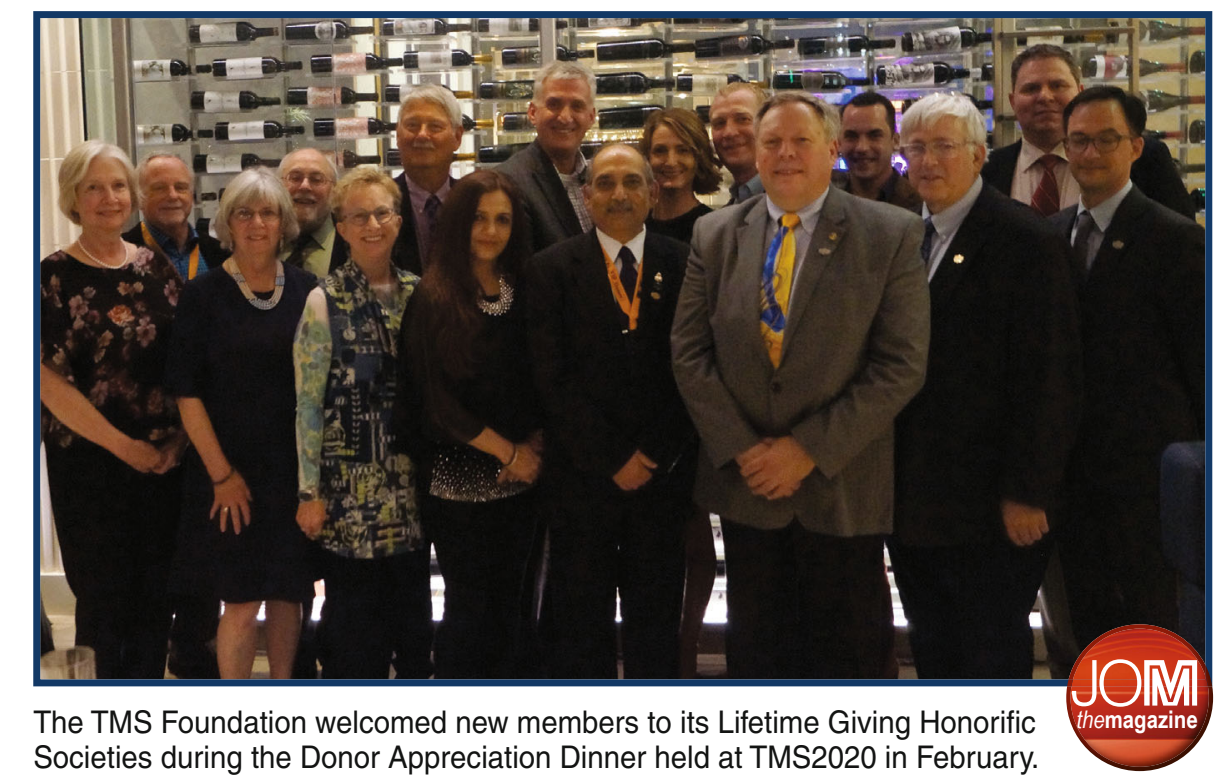

